\title{
Perubahan Perilaku Politik Luar Negeri Tiongkok Terhadap Isu Laut
}

\section{Tiongkok Selatan}

\author{
Arief Bakhtiar Darmawan ${ }^{1}$ \\ arief.darmawan@unsoed.ac.id
}

\begin{abstract}
Abstraksi
Artikel ini bertujuan untuk mengeksplorasi perubahan perilaku politik luar negeri Tiongkok dalam menghadapi sengketa Laut Tiongkok Selatan (LTS) sejak Tiongkok bersedia turut serta dalam forum regional atau multilateral sampai saat ini. Artikel ini berargumen bahwa meski karakter utama dan narasi politik luar negeri Tiongkok cenderung konsisten, perilaku politik luar negeri Tiongkok mengalami perubahan. Penelitian ini menggunakan analisis perbandingan historis yang mengelaborasi pola-pola sejarah dalam politik luar negeri Tiongkok. Melalui metode kualitatif yang menyandarkan pada dokumen resmi, sumber arsip, dan pustaka literatur spesifik tentang politik luar negeri Tiongkok atas LTS, penulis berusaha menganalisis berbagai peristiwa dan detail spesifik perilaku politik luar negeri Tiongkok terhadap isu LTS dari tahun 1990 sampai 2018 ke dalam satu studi yang komprehensif. Perilaku politik luar negeri Tiongkok ketika menghadapi isu LTS terbagi menjadi empat fase. Pertama, fase pasif dan defensif. Tiongkok masih curiga bahwa forum multilateral merupakan cara untuk menekan kepentingan Tiongkok. Kedua, fase aktif. Pada fase ini, Tiongkok mulai percaya diri sebagai negara besar dan kuat sehingga tidak khawatir bahwa forum multilateral akan mengancam keamanan nasionalnya. Ketiga, fase inisiatif. Tiongkok melangkah lebih jauh dengan menginisiasi beberapa ide dan terobosan multilateral yang sangat penting dalam jangka panjang. Keempat, fase asertif. Dalam fase ini, Tiongkok terlibat dalam beberapa insiden, konsisten terhadap kepentingan mereka, sekaligus berusaha menahan diri untuk tidak memulai perang terbuka. Melalui perubahan politik luar negeri tersebut, Tiongkok berhasil menyesuaikan diri dengan politik internasional kontemporer dan tetap berhasil mempertahankan kepentingan nasionalnya atas LTS.
\end{abstract}

Kata kunci: Laut Tiongkok Selatan, politik luar negeri, sengketa, Tiongkok

\begin{abstract}
This article aims to explore China's foreign policy changes on the South China Sea (SCS) dispute ever since China started participating in regional or multilateral forums up to today. This article argues that although the main characters and narratives of China's foreign policy tend to be consistent, Chinese foreign policy behavior is changing. This study uses comparative historical analysis that elaborates historical patterns in Chinese foreign policy. Through qualitative methods that rely on official documents, source of archives, and specific literature about China's foreign policy on SCS, the authors attempt to analyze various events and specific details of Chinese foreign policy behavior on the SCS issue from 1990 to 2018 into one comprehensive study. China's foreign policy behavior on the issue of SCS is divided into four phases. First, the passive and defensive phases. China still suspects that multilateral forums are a way of suppressing Chinese interests. Second, the active phase. In this phase, China begins to believe in itself as a big and powerful country that they do not consider multilateral forums as a threat its national security. Third, the initiative phase. China goes a step further by initiating some important multilateral initiative and breakthroughs in the long-term project. Fourth, the assertive phase. In this phase, China is involved in several incidents, consistent with their
\end{abstract}

1 Korespondensi: Program Studi Hubungan Internasional Universitas Jenderal Soedirman,Jl. Prof. Dr. HR. Boenjamin 708 - Purwokerto 53122 / Hot line: (0281) - 635292 
interests, while trying to refrain from initiating an open war. Through the change of foreign policy, China has adjusted to contemporary international politics and maintained its national interest in SCS.

Keywords: China, dispute, foreign policy, South China Sea

\section{Pendahuluan}

Dalam perjalanannya sebagai sebuah negara, Tiongkok terus mengalami perubahan perilaku politik luar negeri. Dalam hubungan internasional kontemporer, kebangkitan Tiongkok merupakan tema yang menarik minat para pengamat dan peneliti (Shambaugh, 2013; Zhao, 2013; Luttwak, 2012). Sekitar 40 tahun lalu, Tiongkok menerapkan kebijakan yang tidak efisien, cenderung stagnan, dan terasing dari ekonomi global. Namun, semenjak Deng Xiaoping melakukan reformasi ekonomi, investasi, dan perdagangan internasional yang berorientasi pasar bebas pada tahun 1979, Tiongkok menjadi negara yang mengalami pertumbuhan pesat di dunia. Pada era Deng Xiaoping, meski masih menerapkan low profile policy, Tiongkok bersikap lebih terbuka terhadap hubungan dengan Jepang dan Amerika Serikat (AS). Hasilnya, dari tahun 1976 sampai 2016, Tiongkok mengalami rata-rata pertumbuhan ekonomi sebesar 9,6\% (Morrison, 2018: 5). Dimulai dari bidang ekonomi tersebut, Tiongkok turut mengubah haluan politik luar negerinya, baik dalam lingkup regional maupun internasional. Perubahan perilaku politik luar negeri Tiongkok tersebut juga berpengaruh dalam sikap Tiongkok ketika menghadapi isu Laut Tiongkok Selatan (LTS). Seperti yang akan penulis paparkan secara lebih mendetail pada bagian pembahasan, Tiongkok yang selalu bersikap defensif dan memiliki kecurigaan terhadap pertemuan-pertemuan multilateral tentang LTS berubah menjadi negara yang berani mengajukan inisiatif terkait dengan upaya penyelesaian sengketa.

Persoalan LTS merupakan isu penting dalam hubungan internasional, baik saat ini maupun di masa depan, karena isu tersebut dapat berpengaruh terhadap stabilitas politik dan keamanan di kawasan Asia Tenggara. Posisi LTS yang strategis sebagai jalur pelayaran dan perdagangan dunia membuat wilayah ini rawan terhadap benturan kepentingan antarnegara. Apalagi, LTS diperkirakan memiliki potensi cadangan sumber daya minyak yang besar, sekitar 28 miliar barel (Weatherbee, 2005: 134). Tiongkok merupakan salah satu pihak yang melakukan klaim, bersama Filipina, Malaysia, Vietnam, Taiwan, dan Brunei Darussalam. Sampai saat ini, klaim-klaim 
antarnegara tersebut belum menemukan titik temu. Sengketa LTS bahkan berpotensi menarik kekuatan-kekuatan maritim eksternal di luar kawasan (Darmawan \& Mahendra, 2018: 99). Meski demikian, ketika berhadapan dengan isu LTS, Tiongkok tidak begitu saja menghindar. Dalam beberapa pertemuan regional yang membahas LTS, Tiongkok bersedia untuk hadir dan membicarakan persoalan yang muncul. Sikap Tiongkok tersebut berbeda dengan sikap Tiongkok di masa lalu ketika masih dipenuhi kecurigaan bahwa kehadiran mereka hanya akan menjadi target kecaman negara-negara lainnya.

Berkaitan dengan hal itu, penulis berusaha memahami bagaimana perubahan kebijakan luar negeri Tiongkok dalam menghadapi isu Laut Tiongkok Selatan. Penulis berargumen bahwa, dengan karakter dan narasi politik yang konsisten, politik luar negeri Tiongkok dalam menghadapi isu Laut Tiongkok Selatan berubah dari low profile policy menjadi cenderung asertif. Meski seringkali dianggap agresif, Tiongkok juga menahan diri untuk tidak memicu perang terbuka antarnegara di area sengketa. Kebangkitan Tiongkok membutuhkan stabilitas kawasan, sehingga Tiongkok berhati-hati untuk melakukan kebijakan yang bersifat pengerahan militer besar-besaran di LTS. Namun, dalam setiap politik luar negerinya, Tiongkok relatif mampu untuk terus mempertahankan kepentingan nasionalnya terhadap isu LTS.

\section{Tinjauan Pustaka}

Sebagai sebuah negara, Tiongkok memiliki tiga karakter yang nantinya akan membantu pemahaman kita mengenai hal-hal yang mempertajam perilaku politik luar negerinya (Varrall, 2015:3-5). Kualifikasi-kualifikasi ini merupakan karakter yang secara khusus melekat dalam politik luar negeri Tiongkok. Pertama, mengenai tujuan utama. Tujuan utama politik luar negeri Tiongkok adalah untuk menjaga Partai Komunis Tiongkok tetap berada di puncak kekuasaan. Dengan demikian, segala tindakan atau kebijakan yang diambil Tiongkok merupakan alat untuk mempertahankan legitimasi. Atau, dengan kata lain, perilaku Tiongkok selalu berada dalam lingkup dan kepentingan Tiongkok sebagai negara satu partai. Jika menilik politik dalam negeri, segala kebijakan negara dalam hal mekanisme sosialisasi, artikelartikel di media, sampai sistem pendidikan, semuanya mengarah pada kepentingan partai. Begitu juga politik luar negeri, semuanya mengarah pada parameter rezim yang 
berkuasa. Kedua, narasi-narasi partai harus sampai pada rakyat. Dengan situasi seperti saat ini, sulit untuk menilai apakah narasi pemimpin atau partai diyakini oleh seluruh rakyat. Tiongkok bukan negara yang sepenuhnya totaliter. Mereka membuka kesempatan pada rakyat untuk bebas melakukan perjalanan ke luar negeri dan mengakses berbagai informasi. Untuk menghadapi ketidakpastian itu, negara dan partai terus mengaitkan isu LTS dengan gagasan nasionalisme yang tertanam kuat dalam kehidupan masyarakat Tiongkok (Sinaga, 2015: 136; Darmawan, 2018: 23). Ketiga, faktor-faktor lain seperti ide pemimpin. Para pemimpin Tiongkok mungkin memiliki tujuan politik luar negeri jangka panjang yang sama. Namun, seperti yang akan kita bahas di bawah, cara-cara yang ditempuh tidak selalu sama. Oleh karena itu, sangat sulit untuk mengatakan bahwa hanya satu faktor yang menentukan perilaku politik luar negeri Tiongkok.

Lebih jauh, Varrall (2015: 5-10) menilai beberapa narasi yang mempertajam politik luar negeri Tiongkok. Pertama, Tiongkok percaya bahwa negara itu telah mengalami 100 tahun penderitaan akibat penjajahan Barat. Oleh karena itu, sebagai bagian dari kampanye patriotik, Tiongkok harus bangkit di arena internasional. Kedua, seperti yang pernah dinyatakan oleh Xi Jinping dalam pidatonya di Jerman tahun 2014, Tiongkok percaya bahwa mereka adalah “a peace-loving nation”. Perdamaian, persahabatan, dan harmoni merupakan bagian yang tidak terpisahkan dari karakter Tiongkok. Xi Jinping mengutip aksioma Tiongkok: "A warlike state, however big it may be, will eventually perish" (MOFA of the PRC, 2014). Ketiga, pandangan terhadap sejarah. Menurut narasi ini, dalam sejarah panjang dunia, Tiongkok adalah kekuatan yang kuat, dihormati, dan aktor global yang damai. Keempat, relasi Tiongkok dan rakyatnya bagaikan orang tua dan anaknya. Dalam konteks ini, aspirasi dari rakyat dipandang layaknya aspirasi keluarga yang akan bersama-sama mewujudkan mimpi bersama Tiongkok. Dua faktor tambahan yang mempertajam politik luar negeri Tiongkok di era kontemporer adalah peran Xi Jinping dan tumbuhnya kapabilitas Tiongkok (Varrall, 2015: 13). Sejak berada di puncak kekuasaan tertinggi, Xi Jinping membawa Tiongkok ke dalam ambisi besar menuju sebuah negara maju. Xi, misalnya, mendorong Tiongkok untuk menjalankan Belt and Road Initiative (BRI) dengan segala resikonya. Pertumbuhan kapabilitas Tiongkok secara ekonomi dan militer juga menjadikan Tiongkok semakin percaya diri dalam hubungan internasional. Sebagai contoh, Tiongkok terus berusaha 
mempertahankan integritas teritorialnya di wilayah LTS. Meskipun tidak memiliki fondasi legalitas yang jelas, Tiongkok terus bertahan atas klaimnya di LTS berdasarkan alasan-alasan historis (Hayton, 2018: 2).

Dengan karakter dan narasi tersebut, politik luar negeri Tiongkok mengalami beberapa perubahan perilaku. Economy (2010: 142) menyatakan bahwa Tiongkok telah menjadi kekuatan yang revolusioner. Dimulai sejak kepemimpinan Deng Xiaoping, Tiongkok membangun keterhubungan dengan dunia luar. Tiongkok mulai percaya bahwa untuk memenuhi kebutuhan dalam negeri, mereka membutuhkan strategi global yang lebih aktif. Perubahan politik luar negeri Tiongkok juga tumbuh dari kesadaran bahwa kekuatan nasional dan posisi geografis yang selama ini telah dilakukan tidak mampu lagi beradaptasi dengan situasi internasional kontemporer (Zhao, 2013). Dalam konsep perubahan dan kesinambungan politik luar negeri, strategi dapat dikatakan berubah jika ada hal-hal mendasar yang menunjukkan perbedaan dari strategi sebelumnya. Perubahan ini bisa mencakup pergeseran posisi negara dalam komunitas internasional maupun perubahan implementasi kebijakan yang berbentuk program tertentu (Rosati, Hagan, \& Sampson, 1994). Sementara itu, kesinambungan bisa dilihat dari landasan politik luar negeri yang konsisten dengan perubahan pada sisi perifer yang tidak terlalu kentara.

\section{Metode Penelitian}

Pendekatan penelitian perubahan perilaku politik Tiongkok ini menggunakan analisis perbandingan historis (comparative historical analysis). Analisis perbandingan historis memformulasikan satu rumusan masalah utama dalam kasuskasus sejarah spesifik yang kemudian dielaborasi melalui pemeriksaan peristiwaperistiwa atau kondisi sejarah tertentu sesuai kurun waktu yang ditentukan peneliti (Neuman, 2014: 52; Mahoney \& Reuschemeyer, 2003: 9). Dalam penelitian ini, rumusan pertanyaan utama dan sejarah spesifik yang dimaksud adalah bagaimana perubahan politik luar negeri Tiongkok terhadap sengketa LTS. Oleh karena itu, penelitian ini termasuk dalam kategori case-oriented comparative research yang fokus pada satu fenomena utama (Ragin, 1987). Dengan analisis perbandingan sejarah, peneliti berusaha mengeksplorasi beberapa periode sejarah politik luar negeri Tiongkok, mengamati keterhubungan dan perbedaan karakteristik tiap periode, serta 
mendeskripsikannya dalam beberapa kategori analisis dengan menyimpulkan fase-fase tertentu. Pendekatan perbandingan historis dalam artikel ini menggunakan metode penelitian kualitatif. Metode kualitatif dalam penelitian melibatkan dugaan-dugaan naratif yang tidak mengandalkan data-data numerik (Spray \& Roselle, 2016: 39). Dalam analisis perbandingan sejarah, penulis melakukan riset dengan mencatat dokumen sejarah dan sumber-sumber arsip. Penulis membatasi dokumen, sumber arsip, serta literatur pada topik yang terkait dengan politik luar negeri Tiongkok, kebangkitan Tiongkok, serta dinamika sengketa LTS. Sekuen waktu juga menjadi pertimbangan pengambilan data. Penulis memulai data politik luar negeri Tiongkok dari kesediaan Tiongkok untuk mengikuti pertemuan multilateral dimulai dari pernyataan Perdana Menteri Tiongkok Li Peng pada bulan Agustus 1990 di Singapura. Dalam pertemuan tersebut, Tiongkok siap mengesampingkan masalah kedaulatan dalam LTS dan ingin bekerja sama dengan negara lain untuk pengembangan bersama masalah maritim atau sumber daya di dalamnya. Li Peng mengatakan, "China is ready to join efforts... to develop islands, while putting aside for the time being the question of sovereignty" (Hyer, 1995: 40). Dari situ, penulis berusaha memahami fase politik luar negeri Tiongkok sampai saat ini.

\section{Hasil dan Pembahasan}

Dalam isu LTS, Tiongkok selalu memperbarui klaim territorial di LTS. Pada tahun 1936, Dewan Editor China Geographical Society dan ahli geografi Bai Meichu membuat atlas Tiongkok yang menggambarkan klaim berbentuk " $U$ " di LTS. Berdasarkan peta tersebut, pada tahun 1947, Departemen Geografi Tiongkok mempublikasikan LTS sebagai bagian dari Distrik Khusus Hainan (Hayton, 2014; Yu, 2003). Pada tahun 1958, Tiongkok mengeluarkan klaim resmi dalam Declaration of China's Territorial Sea yang memasukkan semua kepulauan di LTS sebagai lautan Tiongkok (Dupuy \& Dupuy, 2013: 126). Klaim itulah yang coba dipertahankan melalui politik luar negeri Tiongkok. Pada bagian ini, penulis menganalisis perubahan politik luar negeri Tiongkok dalam merespon isu LTS. Perubahan yang dibahas meliputi keikutsertaan Tiongkok dalam forum multilateral untuk menyelesaikan masalah dan mencari persetujuan damai di LTS maupun perilaku-perilaku Tiongkok di lautan. Dalam bab ini, berdasarkan pola dan level keterlibatan, penulis membahas perilaku Tiongkok dalam empat fase utama. 


\section{Fase Pertama (1990-1995): Pasif dan Defensif}

Pada fase pertama ini, Tiongkok masih berhati-hati untuk terlibat dalam pertemuan atau perundingan multilateral. Sikap Tiongkok masih dipenuhi rasa curiga bahwa pertemuan-pertemuan multilateral berusaha untuk menekan kepentingan Tiongkok. Pada masa ini, mengutip Marc Lanteigne (2009: 21), politik luar negeri Tiongkok masih dipengaruhi oleh low profile policy yang dibawa Deng Xiaoping, yaitu "biding China's capabilities and biding its time" (tanguangyanghui). Oleh karena itu, Tiongkok berperilaku pasif dan defensif. Kata "pasif" di sini berkaitan dengan kekuatan suatu negara, sehingga makna pasif dapat dipahami sebagai keinginan untuk tidak menunjukkan kekuatan untuk mendominasi. Sementara kata “defensif” merujuk pada sikap khawatir Tiongkok dalam menghadapi tantangan atau kritik dari negara lain.

Pada awalnya Tiongkok hanya mengikuti forum multilateral yang bersifat informal, yaitu Managing Potential Conflicts in the South China Sea (MPCSCS). MPCSCS mulai diselenggarakan pada tahun 1990, diinisiasi oleh diplomat Hasjim Djalal dari Indonesia dan Profesor Ian Towsend-Gault dari Kanada yang merancang lokakarya informal atau tidak resmi yang membicarakan LTS (Djalal, 2011). Tiongkok baru mengikuti MPCSCS pada pertemuan yang kedua. Pada pertemuan MPCSCS yang kedua, semua negara di kawasan ikut serta hadir di Bandung kecuali Kamboja. Kamboja masih menghadapi situasi dalam negeri yang tidak stabil. Kamboja baru berpartisipasi dalam MPCSCS pada tahun 1994 ketika negara tersebut menyelenggarakan pemilu yang disponsori oleh UNTAC. Dalam pertemuan ini, Tiongkok bersikap defensif dan penuh kehati-hatian. Dalam kesempatan yang diberikan, pimpinan delegasi Tiongkok Direktur Asia dalam Kementerian Luar Negeri Tiongkok Wang Yingfan menegaskan bahwa kehadiran Tiongkok tidak mengindikasikan perubahan posisi Tiongkok atas Kepulauan Paracel dan Kepulauan Spratly. Tiongkok tetap pada posisinya bahwa Tiongkok memiliki kedaulatan atas dua kepulauan tersebut. Setidaknya ada lima poin penting yang disampaikan Wang Yingfan. Pertama, Tiongkok siap untuk mengadakan kerja sama eksplorasi melalui mekanisme atau organisasi yang sesuai. Kedua, Tiongkok menyatakan persetujuannya bahwa masalah LTS harus diselesaikan secara damai. Ketiga, Tiongkok menghimbau negaranegara lain untuk tidak memperkeruh situasi di lapangan. Keempat, Tiongkok tidak 
setuju jika masalah LTS harus diselesaikan melalui mekanisme organisasi internasional dan memilih untuk menyelesaikannya secara bilateral. Kelima, Tiongkok tidak ingin ada kekuatan atau negara di luar kawasan yang terlibat dalam resolusi konflik teritorial di LTS. Menurut John Garver, kebijakan Tiongkok dalam isu LTS tersebut merupakan usaha Tiongkok untuk mencegah naiknya tensi konflik di kawasan (Garver, 1992: 1016).

Pada lokakarya MPCSCS ketiga yang diselenggarakan pada tahun 1992 di Yogyakarta, Tiongkok bersikap defensif ketika forum mulai membahas tindakan Tiongkok yang memperbolehkan kerja sama eksplorasi minyak antara China National Offshore Oil Corporation (CNOOC) dan perusahaan minyak AS Crestone Energy Corporation di perairan sengketa. Tiongkok meminta forum tidak membicarakan persoalan tersebut. Pada pertemuan MPCSCS ke-4 tahun 1993 di Surabaya, Menteri Luar Negeri Indonesia Ali Alatas sempat mengusulkan untuk membuat lokakarya ini menjadi pertemuan formal, namun Tiongkok menolak dengan alasan bahwa isu LTS akan menjadi lebih sulit dan kompleks (Shaohua, 2008: 87). Pada pertemuan ini, Tiongkok kembali meminta lokakarya tidak membahas isu kedaulatan dan politik di LTS. Oleh karena itu, pada pertemuan MPCSCS ke-5 tahun 1994 dan selanjutnya, diskusi mengenai isu-isu politik dan keamanan tidak dimasukkan dalam agenda lokakarya. Perkembangan mengenai isu politik dan keamanan tidak banyak berarti. Tiongkok juga menolak usulan Indonesia mengenai “formula donat" yang menempatkan area tengah LTS sebagai lokasi proyek pengembangan bersama. Tiongkok khawatir klaimnya akan terganggu (Shaohua, 2008: 76-77). Pada pertemuan yang ke-4, Menteri Luar Negeri Indonesia Ali Alatas mengusulkan agar lokakarya melibatkan negara lain seperti AS, Jepang, atau negara Eropa untuk membantu proyek kerja sama dari sisi teknis atau finansial. Tiongkok menolak meskipun tidak menutup kemungkinan di masa depan (Haryanto \& Bainus, 2017: 75).

Selain dalam MPCSCS, kehati-hatian Tiongkok terlihat pada tahun-tahun awal ASEAN Regional Forum (ARF). Tiongkok pertama kali ikut serta sebagai “consultative partner" untuk Association of Southeast Asian Nations (ASEAN) dalam pertemuan pertama ARF di Bangkok pada 25 Juli 1994. Forum ini dibentuk setelah disepakati oleh para pemerintah negara-negara ASEAN dalam Pertemuan Menteri ASEAN yang diselenggarakan pada 23-25 Juli 1993 (Kemlu RI, 2012). Isu LTS 
mendapatkan tempat dalam pembahasan pertemuan ARF karena hal ini sesuai dengan tujuan ARF dibentuk, yaitu "to foster constructive dialogue and consultation on political and security issues of common interest and concern" dan "to make significant contributions to efforts towards confidence-building and preventive diplomacy in the Asia-Pacific region" (ASEAN Regional Forum, 2018). Pembicaraan antarnegara di dalam ARF, baik yang terlibat klaim maupun tidak, menjadi penting karena isu LTS melibatkan banyak pihak, terutama yang berkaitan dengan kebebasan navigasi di lautan tersebut. Pihak-pihak yang tidak terlibat klaim langsung pun berkepentingan dalam mencari penjelasan dan perkembangan mengenai isu LTS karena khawatir efek buruknya akan menyebar luas jika terjadi konflik terbuka.

Pada awal mula diskusi pembentukan ARF, ada tiga kekhawatiran para pemimpin Tiongkok yang membuat Tiongkok tidak antusias dengan ARF. Pertama, Tiongkok merasa bahwa negara-negara di Asia memiliki banyak perbedaan dan waktunya tidak tepat. Kedua, Tiongkok khawatir masalah Taiwan dan klaim di LTS akan menjadi bagian dari pembicaraan multilateral. Ketiga, ARF berpotensi mengancam kepentingan Tiongkok yang lain, yaitu dengan adanya kekuatan luar kawasan yang ikut campur terlalu dalam mengenai isu LTS. Tiongkok khawatir AS akan mendominasi proses organisasional dalam ARF dan mengkritik perilaku-perilaku Tiongkok (Foot, 1998: 426). Sementara itu, beberapa negara ASEAN meminta forum untuk fokus pada masalah-masalah umum ketimbang isu-isu yang bisa menimbulkan perdebatan dan menempatkan salah satu pihak dalam posisi defensif karena kritik. Malaysia dan Filipina adalah dua negara yang memperlihatkan keinginan untuk mendiskusikan masalah politik dan keamanan dalam konflik LTS. Dalam konferensi pers mengenai ARF, Tiongkok merespon sikap dua negara ASEAN tersebut dengan menegaskan bahwa konflik teritorial tidak seharusnya mendapat tempat di ruang diskusi ARF. Pada akhirnya, pernyataan yang paling penting adalah pentingnya untuk meninggalkan penggunaan senjata nuklir di Asia Utara, tanpa menyebutkan mengenai konflik LTS. Beberapa pengamat mulai melihat ARF sebagai "no more than a glorified cocktail party" (Shaohua, 2008: 98).

Dalam perkembangan ARF kemudian, negara-negara besar seperti AS, Rusia, dan India, ikut serta dalam forum dengan dilandasi berbagai kepentingan. AS ingin tetap hadir menjadi kekuatan regional di kawasan, sementara Jepang ingin 
mengamankan pasokan minyak. Hal itu membuat Tiongkok enggan membicarakan masalah LTS ini lebih jauh. Hal tersebut dipertegas dalam pertemuan ARF ke-2 di Brunei tahun 1995. Juru bicara Menteri Luar Negeri Tiongkok mengatakan bahwa Tiongkok “menolak peran ARF dalam mendiskusikan masalah ini” (Acharya, 2009: 134). Pada tahun tersebut, tensi kawasan sempat memanas karena insiden Gugusan Karang Mischief yang melibatkan Tiongkok dan Filipina. Tiongkok sempat mengepung dan menahan kapal Analita yang dipimpin Kapten Alipustain dari Filipina yang memergoki bangunan Tiongkok di Gugusan Karang Mischief. Setelah terlibat dalam perdebatan, Tiongkok akhirnya menyatakan kesediaan untuk menyelesaikan isu LTS dengan negara ASEAN berbasis hukum internasional, namun tanpa keterlibatan dari pihak luar kawasan. Untuk pertama kalinya dalam forum multilateral formal, Tiongkok berdiskusi mengenai konflik LTS dengan ASEAN sebagai satu kelompok. Meskipun kesediaan Tiongkok untuk membicarakan isu LTS dianggap sebagai kesuksesan bagi ARF yang mengubah pendekatan dari "bard approach" menjadi "soft approach", pada fase ini penulis melihat Tiongkok lebih bersikap pasif dan defensif.

\section{Fase Kedua (1996-1999): Aktif}

Pada fase ini, persepsi Tiongkok terhadap forum multilateral secara umum mulai berubah. Tiongkok mulai aktif dalam forum-forum multilateral yang diikutinya. Sama seperti kata “pasif”, kata “aktif” tersebut berkaitan dengan kekuatan suatu negara. Dengan demikian, fase aktif di sini dipahami sebagai perilaku Tiongkok yang mulai merasa percaya diri dengan kekuatan yang dimilikinya dan mencoba untuk menghadapi semua hambatan yang menghalangi kepentingannya atas klaim di LTS. Di bawah kepemimpinan Jiang Zhemin, Tiongkok mulai meninggalkan taoguang yangbui dan mulai menjalankan great power diplomacy (daguo zhanlue) (Lanteigne, 2009: 21). Pada fase ini, Tiongkok pertama kali menempatkan klaimnya di LTS atas dasar historis dalam dokumen resmi China's Exclusive Economic Zone and Continental Shelf Act (Dupuy \& Dupuy, 2013: 123). Tiongkok berargumen bahwa Tiongkok telah hadir di kawasan itu sejak Dinasti Han berkuasa pada abad ke-2 SM (Dam, 2010). Faktor sejarah inilah yang memperkuat keaktifan Tiongkok agar tidak kehilangan klaim. Di saat yang bersamaa, dengan keyakinan bahwa Tiongkok adalah negara besar dan kuat, Tiongkok tidak lagi menganggap bahwa forum-forum multilateral akan memberi tekanan yang besar pada 
keamanan nasionalnya (Cheng-Chwee, 2005: 107). Secara khusus, hal itu berlaku juga untuk forum-forum multilateral yang membicarakan isu LTS. Forum seperti ARF dan MPCSCS yang memakai nilai-nilai ASEAN perlahan membuat Tiongkok merasa nyaman karena adanya prinsip non-intervensi dan pendekatan konsensus dalam pengambilan keputusan.

Keaktifan Tiongkok terlihat dengan jelas dalam ARF. Pada keikutsertaan tahun 1996, status Tiongkok dalam ARF berubah menjadi “dialoguepartner” sepenuhnya. Dalam pertemuan ARF ke-3 tahun 1996, Menteri Luar Negeri Qian Qichen mengemukakan pendekatan kerja sama keamanan yang dikenal dengan New Security Concept (NSP). Tujuan utama NSP adalah "to conduct dialogue, consultation, and negotiation on an equal footing... to solve disputes and safeguard peace. Only by developing a new security concept and establishing a fair and reasonable new international order can world peace and security be fundamentally guaranteed" (Shambaugh, 2013: 78-79). Meskipun Menteri Luar Negeri Qian Qichen mengatakan bahwa posisi Tiongkok yang mengesampingkan perselisihan dan fokus pada pengembangan bersama akan menjadi konsensus dari anggota forum, Tiongkok melangkah lebih jauh dengan kesediaan menjadi tuan rumah Confidence Building Measures (CBM) ARF. Pada tahun 1997, Tiongkok bersama Filipina menjadi ketua “intersessional support group” dalam CBM yang diselenggarakan di Beijing. Menteri Luar Negeri Tiongkok Qian Qichen menyatakan bahwa ini akan menjadi “pertama kalinya bagi Tiongkok untuk menjadi tuan rumah sebuah konferensi multilateral resmi dalam isu keamanan" (Foot, 1998: 426). Dalam ARF ke-4 ini, juru bicara Kementrian Luar Negeri Tiongkok Cui Tiankai mengatakan bahwa Tiongkok bersedia menyelesaikan konflik melalui konsultasi damai dan meminta pengembangan bersama menjadi perhatian peserta forum. Filipina yang menginginkan isu LTS masuk dalam agenda menawarkan proposal untuk membahas resolusi konflik, tapi proposal tersebut tidak mendapatkan respon dari forum. Ketimbang memandang hal tersebut sebagai strategi Tiongkok, penulis memahami bahwa isu LTS tidak menjadi perhatian utama forum karena pada tahun 1997 itu ASEAN menghadapi krisis kepemimpinan di Kamboja dan isu hak asasi manusia di Myanmar. Namun pertemuan di Beijing telah berhasil membahas isu-isu keamanan yang sebelumnya tabu bagi Tiongkok: doktrin pertahanan dan transparansi kekuatan militer, kerja sama militer, partisipasi dalam United Nations Register of Conventional Arms (UNRCA), serta sirkulasi partisipasi UNRCA 
di antara sesama anggota ARF. Pernyataan Menlu Qian mengenai militer dan keamanan pada bulan Juli 1997 juga positif untuk upaya perdamaian: "Security cannot depend on increasing armament. Nor can it depend on military alliance. Security should depend on mutual trust and ties of common interests" (Foot, 1998: 435).

Pada ARF ke-5 di Manila, pada tahun 1998, perdebatan kembali muncul antara Tiongkok dan Filipina terkait insiden Mischief Reef pada tahun 1995. Tuan rumah Filipina ingin agar forum mendukung posisi Filipina masalah pembangunan infrastruktur Tiongkok di Mischief Reef dan melakukan isolasi terhadap Tiongkok. Sementara itu, Tiongkok menjelaskan bahwa pembangunan fasilitas di Mischief Reef untuk tujuan pengamatan cuaca dan akan terbuka bagi nelayan Filipina di masa depan. Proposal Filipina tidak mendapatkan respon positif dari negara-negara ASEAN lainnya. Menteri Luar Negeri Malaysia Syed Hamid Albar, misalnya, mengatakan bahwa situasi di LTS cenderung stabil. Dalam ARF ke-5 ini, Tiongkok kembali konsisten untuk menolak internasionalisasi isu LTS dan setuju untuk menyelesaikan persoalan dalam kerangka damai bersama pihak-pihak yang 'relevan’ saja (Shaohua, 2008: 107). Dalam ARF ke-6 di Singapura, pada tahun 1999, perdebatan yang muncul adalah mengenai bangunan baru atau perluasan struktur di LTS. Filipina mengajukan draf agar tidak boleh ada bangunan baru atau perluasan struktur di LTS oleh negara pengklaim. Semua negara ASEAN menyetujui draf itu untuk dibicarakan dalam ARF, kecuali Malaysia. Namun setelah melalui diskusi kembali, agar Tiongkok bisa menerima hasil ARF, Filipina akhirnya menyetujui bolehnya struktur permanen baru di area konflik (Shaohua, 2008: 108).

Dalam MPCSCS, Tiongkok relatif percaya diri dari sikap negara lain yang berkaitan dengan klaim atas LTS. Dalam MPCSCS ke-9, United Nations Environment Programme (UNEP) sebagai salah satu organ Perserikatan Bangsa-bangsa (PBB) diundang sebagai salah satu narasumber (Bainus, 2000: 28). Meski demikian, kehadiran UNEP tidak serta merta membuat Tiongkok meninggalkan posisinya bahwa penyelesaian sengketa cukup dibicarakan antarsesama negara yang terlibat langsung. Keterlibatan UNEP dalam MPCSCS relatif kecil, sebatas pada proyek biodiversitas. Pada fase ini, Tiongkok terlihat lebih percaya diri dan aktif dalam forum multilateral yang membicarakan isu LTS. 


\section{Fase Ketiga (2000-2011): Berinisiatif}

Tiongkok terus mengalami perubahan dalam perilaku politik luar negerinya. Kata “inisitiatif” yang dipilih penulis pada fase ini merujuk pada sikap negara untuk mempromosikan atau mendorong hal-hal tertentu kepada negara lain. Hal itulah yang terlihat dari politik luar negeri Tiongkok di bawah kepemimpinan Hu Jintao yang memperkenalkan prinsip "harmonious world" (hexie shijie) (Medeiros, 2009: 48). Prinsip tersebut menekankan pada niat Tiongkok untuk "memelihara perdamaian dunia" dan lebih terikat pada komunitas internasional (Medeiros, 2009: 49-50). Dalam isu LTS, prinsip tersebut mendorong Tiongkok melangkah lebih jauh dengan menginisiasi beberapa ide dan mendorong terobosan multilateral yang sangat penting untuk strategi jangka panjang. Pada tahun 2009, Tiongkok sempat mendaftarkan peta Sembilan garis putus-putus berbentuk "U" ke Komisi PBB Bidang Perbatasan dan Landas Kontinen, meskipun kemudian tidak mendapatkan legalisasi (Dupuy \& Dupuy, 2013: 130. Partisipasi Tiongkok yang mengusulkan beberapa proposal dalam forum regional bersamaan dengan fokus Tiongkok pada stabilitas kawasan yang dibutuhkan untuk mendukung pertumbuhan ekonomi domestik Tiongkok sampai tahun 2020 (Yi, 2005: 76). Fase ini merupakan masa terbaik dan paling efektif dalam diplomasi luar negeri Tiongkok (Shambaugh, 2013: 41). Para pengamat melihat Tiongkok menjalankan kebijakan luar negeri "charm offensive" (Lanteigne, 2009: 30).

Dalam ARF ke-7 di Bangkok yang diselenggarakan pada bulan Juli 2000, dua hal penting yang perlu dicatat adalah kehadiran Korea Utara sebagai tamu dan inisiatif ASEAN-Tiongkok untuk membuat "Regional Code of Conduct in the South China Sea". Kehadiran Korea Utara dan Korea Selatan tidak lepas dari peran Tiongkok yang memiliki hubungan dengan kedua negara (Evans, 2003: 753). Dalam pertemuan ARF ke-8 tahun 2001 di Hanoi, Vietnam, para peserta mendiskusikan COC di LTS dan isuisu keamanan lain di Asia Pasifik. Forum sepakat untuk mengadakan konsultasi antara ASEAN dan Tiongkok untuk mengembangkan COC sebagai jalan perdamaian dalam isu LTS. Pada ARF ke-8 tahun 2002 ini, Menteri Luar Negeri Tiongkok menegaskan kembali prioritas kebijakan Tiongkok untuk membangun persahabatan antarnegara dan sikap sebagai negara tetangga yang baik. Pada ARF tahun 2003, Tiongkok mengajukan proposal ARF Security Policy Conference (ASPC). ARF ke-18 di Bali, yang diselenggarakan pada bulan Juli 2011, menghasilkan beberapa kesepakatan antara 
ASEAN dan Tiongkok mengenai komitmen dalam pelaksanaan DOC bagi para pihak di LTS. Secara garis besar, melihat tidak adanya perdebatan besar yang menimbulkan perselisihan dalam forum, ARF telah menjalankan berkomitmen untuk melangkah dan dijalankan dengan nyaman bagi semua partisipan: pelan, tidak mengikat, dan persetujuan diputuskan secara sukarela. Menurut Rosemary Foot, ARF mengadopsi mekanisme kerja sama keamanan yang menempatkan kepercayaan dan dialog sebagai metode untuk menciptakan rasa saling percaya (Foot, 1998: 428).

Pada tahun 2000, ketika Canadian International Development Agency (CIDA) menghentikan bantuan dana untuk MPCSCS, Tiongkok bersedia memberikan bantuan dana untuk keberlanjutan lokakarya tersebut. Para peserta juga sepakat bahwa forum tetap bersifat informal dan metode pengambilan keputusan menggunakan konsensus. Pada kurun waktu antara tahun 2003 sampai 2006, Tiongkok berperan lebih aktif dengan menjadi koordinator proyek Database Information Exchange and Networking.

Pada tahun 2002, ASEAN dan Tiongkok menandatangani DOC yang merupakan deklarasi Tata Berperilaku di sekitar kawasan LTS. Penandatanganan tersebut merupakan keberhasilan lanjutan dari Pertemuan Menteri Luar Negeri ASEAN tahun 1992 di Manila yang menghasilkan ASEAN Declaration on the South China Sea. Deklarasi pada tahun 1992 itu sendiri menegaskan "necessity to resolve all sovereignty and jurisdictional issues pertaining to the South China Sea by peaceful means, without resort to force", dan keinginan "all parties concerned to exercise restraint" (Acharya, 2009: 134). Pada tahun 2005, untuk mengupayakan implementasi DOC yang diinisiasi oleh ASEAN, ASEAN-Tiongkok membentuk kelompok kerja gabungan dan sepakat bahwa kedua belah pihak berkomitmen menjaga perdamaian dan stabilitas di kawasan LTS. Pada Konferensi Tingkat Tinggi (K'TT) ASEAN ke-11 tahun 2007 di Singapura, setelah mengikuti CBM yang tidak mengikutsertakan Taiwan, Tiongkok kembali menandatangani dokumen di bidang politik dan keamanan mengenai isu keamanan non-tradisional dan implementasi DOC (Sinaga, 2011).

Pada tahun 2010, Tiongkok aktif dalam pembicaraan mengenai DOC dan KTT ASEAN. Beberapa kelanjutan pertemuan dari kelompok kerja gabungan mengenai implementasi DOC misalnya ASEAN-China Joint Working Group Meeting on the Implementation of the DOC, yang diselenggarakan di Hanoi, Vietnam, pada 16-17 April 2010. Pertemuan tersebut menetapkan bahwa DOC akan selalu menjadi salah satu 
dokumen yang signifikan bagi ASEAN dan Tiongkok. Oleh karena itu, ASEAN dan Tiongkok harus terus menghormati setiap aspek yang terkandung pada DOC tahun 2002. Tiongkok hadir dalam KT'T ASEAN ke-17 yang diselenggarakan pada 30 Oktober 2010 di Hanoi, Vietnam, yang kembali membahas masalah DOC. Tiongkok ikut menyepakati langkah-langkah penting terkait implementasi DOC, diantaranya memanfaatkan mekanisme regional dalam membangun rasa saling percaya dalam isu LTS dengan mengimplementasikan DOC serta terus mengupayakan Code of Conduct in the South China Sea (COC). Pada akhir tahun 2010, tepatnya tanggal 21-22 Desember, Tiongkok menjadi tuan rumah pertemuan ASEAN-China Joint Working Group Meeting on the Implementation of the DOC di Kunming. Kelanjutan pembicaraan LTS menjadi lebih giat pada tahun 2011. Pada tanggal 17-19 April 2011, Indonesia menjadi tuan rumah untuk pertemuan ke-6 ASEAN-China Joint Working Group on the Implementation of the Declaration on the Conduct of Parties in the South China Sea yang diselenggarakan di Medan. Dalam pertemuan ini, Tiongkok mengambil peran sebagai ketua salah satu agenda pertemuan bersama Vietnam yang juga memiliki klaim di LTS (CIL, 2011).

Inisiatif Tiongkok pada fase ini didukung oleh faktor internal berupa kapabilitas militer dan kebutuhan ekonomi. Secara militer, anggaran militer Tiongkok terus mengalami kenaikan, dari 63.503 juta dollar AS pada tahun 2004 sampai 147.258 juta dollar AS pada tahun 2011 (SIPRI, 2015). Jumlah itu merupakan angka yang sangat besar untuk mengembangkan senjata nuklir dan peralatan militer dengan daya jangkau yang jauh (Darmawan, 2018). Dengan anggaran yang besar dan modernisasi militer, Tiongkok semakin percaya diri untuk mempertahankan klaim. Secara ekonomi, LTS menyimpan banyak potensi untuk meningkatkan pendapatan nasional, misalnya cadangan minyak yang diperkirakan mencapai 28 miliar barrel (Weatherbee, 2005: 134). Selain itu, sejak tahun 2003, Tiongkok telah menjadi konsumen minyak terbesar ke-2 di dunia, sehingga penguasaan jalur pelayaran menjadi isu utama (Medeiros, 2009: 40). Dengan potensi dan pentingnya LTS untuk ekonomi dalam negeri, Tiongkok harus tetap menguasai forum agar sesuai dengan kepentingan mempertahankan klaim.

\section{Fase Keempat (2012-2018): Asertif}

Pada fase ini, Tiongkok memperlihatkan kecenderungan untuk memperkuat kepentingan nasionalnya terhadap isu LTS dalam forum multilateral 
dengan berusaha menolak agenda pembicaraan mengenai isu LTS dalam forum, meskipun juga tetap bersedia mengikut forum multilateral yang membahas LTS. Pada fase ini, Tiongkok bersikap asertif sekaligus tidak mau ambil resiko dengan bersikap arogan. Menurut kamus Meriam-Webster (2018), makna kata asertif merujuk pada pernyataan-pernyataan atau perilaku yang tegas dan percaya diri. Lebih lanjut, perilaku asertif merupakan sikap seseorang "to act in his own best interests, to stand up for bimself without undue anxiety, to express his honest feeling comfortably, or to exercise his own rights without denying the rights of others". Dalam konteks hubungan internasional, sampai saat ini belum ada konsensus mengenai makna asertif (Johnston, 2013: 9). Beberapa merujuk pada aktivisme yang konstruktif, beberapa lainnya mendeskripsikannya serupa perilaku imperialistik atau nasionalistik. Dalam konteks perilaku Tiongkok, sementara Johnston (2013: 10) memahami asertif sebagai ancaman yang eksplisit terhadap aktor lain jika tidak ingin mendapatkan kerugian yang lebih besar, Jerdén (2014: 49) melihatnya sebagai tendensi Tiongkok untuk meraih tujuan dan menyelesaikan persoalan dengan cara konfrontatif. Dalam artikel ini, penulis memahami sikap asertif Tiongkok sebagai perilaku untuk meraih kepentingannya di LTS, bahkan jika perlu menggunakan caracara konfrontatif.

Indikasi sikap asertif ditunjukkan dalam beberapa hal. Pada bulan Juni 2014, misalnya, Tiongkok menerbitkan peta resmi baru dengan menambahkan garis putus-putus ke-10 di sebelah timur Taiwan (Hayton, 2014). Tiongkok juga berhasil mendikte forum. Pada Pertemuan Menlu ASEAN yang diselenggarakan bulan Juli 2012, Tiongkok mempengaruhi ketua ASEAN tahun itu, Kamboja, untuk tidak membahas isu LTS. Hal itu semakin mempertajam sikap ASEAN yang telah terbelah (Darmawan \& Mahendra, 2018). Pertama kalinya dalam sejarah ASEAN tidak menghasilkan dokumen apa pun. Dalam pertemuan itu, konsensus antarnegara ASEAN tidak tercapai. Kamboja melalui Menlu Hor Namhong menolak memasukkan insiden antara Tiongkok-Filipina di Beting Scarborough ke dalam dokumen akhir forum (BBC, 2012). KTT ASEAN ke-23 di Bandar Seri Begawan, Brunei, pada 24 April 2013 kembali membicarakan masalah LTS. Sebelum KTT, terjadi dua insiden di wilayah sengketa yang semuanya melibatkan Tiongkok, yaitu antara Tiongkok-Vietnam dan Tiongkok-Malaysia. Oleh karena itu, dalam pertemuan tersebut, negara-negara ASEAN berusaha mengajak Tiongkok untuk menyetujui COC atau tata berperilaku 
dalam penyelesaian masalah di LCS. Namun Tiongkok menolak karena tidak ingin ada ikatan yang lebih ketat untuk mengatur tindakannya di LTS. Tiongkok khawatir adanya COC akan mengganggu klaim teritorialnya di LTS. KT'T ASEAN ke-24 tahun 2004 di Naypydaw, Myanmar, menjadikan isu sengketa LTS sebagai pembahasan utama. Salah satu sebabnya, sebelum KTT, insiden di wilayah LTS kembali terjadi antara Tiongkok dan Vietnam (The Guardian, 2014). Sikap asertif kembali terlihat ketika pada bulan Juli 2014, surat kabar Harian Rakyat yang merupakan corong Partai Komunis Tiongkok menerbitkan peta baru LTS dengan sepuluh garis putus-putus (Reuters, 2014). Penerbitan peta tersebut penting supaya rakyat memahami upaya-upaya pemerintah demi hak-hak maritim dan integritas territorial (Darmawan, 2018). Media dalam negeri juga menempatkan Tiongkok sebagai korban agresivitas Vietnam dan Filipina untuk menumbuhkan sikap nasionalisme (International Crisis Group, 2012: 27).

Pada tahun 2015, dalam Pernyataan Bersama Pertemuan Tingkat Menteri Luar Negeri ASEAN yang diselenggarakan pada bulan Agustus 2015 di Kuala Lumpur, isu LTS mendapatkan perhatian yang serius. Sebelum pertemuan tersebut, Menlu Tiongkok Wang Yi dan Wakil Menlu Tiongkok Liu Zhenmin meminta forum untuk tidak membahas isu LTS. Menurut Wakil Menlu Liu Zhenmin, forum tersebut adalah forum untuk mempromosikan kerja sama (South China Morning Post, 2015). Tapi ASEAN menolak dan akhirnya memasukkan isu LTS dalam Pernyataan Bersama. Para Menlu ASEAN menegaskan telah "mencatat perhatian yang serius yang disampaikan beberapa menteri mengenai pengurukan daratan di Laut Tiongkok Selatan, yang telah mengikis kepercayaan, meningkatkan ketegangan, serta mengurangi perdamaian, keamanan, dan stabilitas di Laut Tiongkok Selatan". Pada akhirnya, sehari sebelum Pernyataan Bersama, Menlu Wang Yi mengatakan bahwa pembangunan yang dimaksud dalam forum telah dihentikan, dan Tiongkok tetap berkomitmen dalam kebebasan navigasi dan penerbangan, serta bersedia mempercepat konsultasi mengenai COC (MOFA of the PRC, 2015). Pada bulan November 2015, sebelum Asia-Pacific Economic Cooperation (APEC), Menteri Luar Negeri Tiongkok Wang Yi mengunjungi Filipina untuk memperingatkan Filipina sebagai tuan rumah APEC agar tidak memasukkan isu teritorial dalam forum APEC. Tiongkok menganggap pembicaraan isu LTS sebaiknya dilakukan secara bilateral dan tidak dalam APEC yang berpotensi melibatkan intervensi negara luar kawasan seperti AS. 
Di lautan, Tiongkok memperlihatkan diri sebagai kekuatan maritim regional yang terus bertumbuh (Burnay, et al., 2015: 29). Jika pada tahun 1990 Tiongkok memiliki anggaran militer sebesar 19,7 juta dollar AS, pada tahun 2014 jumlah itu menjadi 190,9 juta dollar AS (SIPRI, 2015). Pada periode ini, Tiongkok terus mengembangkan senjata nuklir serta kapal militer yang memiliki kemampuan daya jangkau yang jauh. Tiongkok terlibat beberapa insiden, baik dengan sesama negara pengklaim maupun AS. Pada tahun 2005, kapal Tiongkok dilaporkan menembaki dua kapal nelayan Vietnam di sekitar Teluk Tonkin. Pada tahun 2012, Tiongkok dan Filipina terlibat konflik di Beting Scarborough. Pada tahun 2009, Tiongkok bahkan sempat terlibat insiden dengan AS. Waktu itu, kapal Tiongkok membayangi kapal AS untuk segera pergi dari kawasan yang diklaim oleh Tiongkok. Pada fase ini, Tiongkok bertindak lebih jauh dengan melakukan proyek reklamasi di LTS. Pada tahun 2015, Tiongkok dilaporkan telah mengubah Gugusan Karang Mischief menjadi sebuah pulau. Tiongkok juga mendirikan landasan terbang kecil di Gugusan Karang Fiery Cross. Peristiwa-peristiwa tersebut mengindikasikan bahwa Tiongkok semakin asertif di bawah kepemimpinan Xi Jinping (Sinaga, 2015: 137).

Dengan analisis kesinambungan dan perubahan dalam pembahasan di atas, penulis mengamati beberapa poin penting. Sejak memutuskan untuk mengikuti perundingan multilateral/ regional yang membahas isu LTS, Tiongkok berhasil mempertahankan kesinambungan klaim mereka atas LTS. Meski mendapatkan tentangan dari negara pengklaim lain seperti Filipina dan Vietnam, Tiongkok tidak pernah kehilangan klaim yang didasarkan atas klaim sejarah tersebut. Hal ini semakin menguatkan Tiongkok sebagai negara yang lekat dengan narasi sejarah. Kesinambungan itulah yang terus dibangun oleh para pemimpin Tiongkok yang juga merupakan para pejabat Partai Komunis Tiongkok. Surat-surat kabar seperti Harian Rakyat (People's Daily) juga terus memberitakan isu LTS dalam konteks nasionalisme, misalnya dengan membuat narasi Tiongkok sebagai korban dari agresivitas Vietnam dan Filipina. Sementara itu, karakter ide-ide pemimpin Tiongkok memengaruhi adanya perubahan perilaku pada masing-masing politik luar negeri. Perubahan perilaku terhadap isu LTS merupakan salah satu cara para pemimpin Tiongkok untuk menyesuaikan diri terhadap lingkungan internasional yang dinamis. Pada awalnya, low profile policy mungkin cocok dengan situasi Tiongkok yang belum terlalu aktif dalam 
arena internasional. Namun, seiring masuknya Tiongkok dalam arena internasional dalam berbagai bidang dan panasnya tensi regional karena LTS, kebijakan itu tidak mampu lagi meredam tensi kawasan. Oleh karena itu, Tiongkok berusaha melakukan beberapa inisiatif dan bertindak asertif untuk secara efektif mempertahankan klaim di LTS sekaligus menjaga hubungan dengan negara-negara ASEAN. Di sini, isu LTS tidak boleh menjadi penghalang bagi kemajuan Tiongkok, yang nantinya beresiko menurunkan legitimasi Partai Komunis Tiongkok di dalam negeri. Tiongkok memandang bahwa isu LTS berada dalam kerangka yang lebih besar lagi, yaitu menjadi bagian dari ide kebangkitan Tiongkok (Fangyin, 2016).

\section{Kesimpulan}

Politik luar negeri Tiongkok terus mengalami perubahan. Meskipun memiliki karakter dan narasi yang sama dari masa ke masa, perubahan perilaku menunjukkan bahwa Tiongkok memperhatikan kapabilitas militer dan ekonominya yang terus meningkat sebagai motivasi dan kekuatan untuk mempertahankan kepentingan nasionalnya. Dalam soal LTS, tujuan strategis Tiongkok atas LTS cenderung berada di pertengahan. Tiongkok mendorong status quo sambil terus bersedia duduk di meja perundingan, baik perundingan regional maupun multilateral. Tiongkok berperilaku agresif di lautan, sekaligus memanfaatkan forum multilateral atau regional untuk mendapatkan kepercayaan dan mempertahankan stabilitas kawasan demi pertumbuhan ekonomi. Fase-fase perilaku politik luar negeri di atas menunjukkan bahwa, mengutip argumen Shannon Tiezzi, "China's rise is peaceful but China will not hesitate to use whatever means necessary to defend itselt' (Rustandi, 2016: 6).

Dengan cara-cara tersebut, Tiongkok berhasil meraih setidaknya empat kepentingan yang sesuai dengan karakter dan narasi Tiongkok mengenai politik luar negeri. Pertama, sejak menerbitkan peta klaim, Tiongkok tidak pernah kehilangan klaim teritorial atas LTS. Kedua, Tiongkok hampir selalu berhasil mendikte forum untuk tidak merusak klaim teritorial yang selama ini dibangun. Ketiga, Tiongkok memperlihatkan diri bahwa peningkatan kapabilitas ekonomi dan militer mereka tidak lantas membuat mereka menarik diri dari isu LTS. Keempat, Tiongkok mampu mencegah kekuatan besar dari luar kawasan untuk ikut campur dalam isu LTS, terutama AS dan Jepang. 


\section{Daftar Rujukan}

\section{Buku}

Acharya, A. (2009). Constructing a Security Community in Southeast Asia: ASEAN and The Problem of Regional Order, $2^{\text {nd }}$ ed. New York: Routledge.

Hayton, B. (2014). The South China Sea: The Struggle for Power in Asia. New Haven \& London: Yale University Press.

Haryanto, A. \& Bainus, A. (2017). Peran Indonesia dalam Sengketa Laut Tiongkok Selatan. Purwokerto: Universitas Jenderal Soedirman.

Lanteigne, M. (2009). Chinese Foreign Policy: An Introduction. London \& New York: Routledge.

Luttwak, E. N. (2012). The Rise of China vs the Logic of Strategy. Cambridge, MA: Belknap Press of Harvard University Press.

Mahoney, J. \& Rueschemeyer, D. (Ed.). (2003). Comparative Historical Analysis in the Social Sciences. Cambridge, U.K.: Cambridge University Press.

Medeiros, E. S. (2009). China's International Behavior: Activism, Opportunism, and Diversification. Santa Monica: RAND Corporation.

Neuman, W. L. (2014). Social Research Methods: Qualitative and Quantitative Approaches. Essex: Pearson Education Limited.

Ragin, C. C. (1987). The Comparative Method. Berkeley, C.A.: University of California Press.

Shambaugh, D. (2013). China Goes Global: The Partial Power. New York: Oxford University Press.

SIPRI, 2015. SIPRI Year Book 2015: Armaments, Disarmaments, and International Security. Stockholm International Peace Research Institute: Oxford University Press.

Spray, S. \& Roselle, L. (2016). Research and Writing in International Relations. New York: Routledge.

Weatherbee, D. E. (2005). International Relations in Southeast Asia: The Struggle for Autonomy. Lanham: Rowman \& Littlefield Publishers, Inc.

\section{Artikel}


Bainus, A., et.al. (2000). Prospek Joint Development dan Joint Co-operation di Laut Cina Selatan sebagai Mekanisme Penghindaran Konflik di Kawasan: Suatu Perspektif Ekonomi-Politik dan Pertahanan dari Indonesia (2001-2003). Final Draft Penelitian. Bandung: Universitas Padjadjaran.

Burnay, M., et al. (2015). China's foreign policy and external relations. Belgium: European Parliament's Committee on Foreign Affairs.

Cheng-Chwee, K. (2005). Multilateralism in China's ASEAN Policy: Its Evolution, Characteristics, and Aspiration. Contemporary Southeast Asia, 27(1), 102-122. Darmawan, A. B. \& Mahendra, L. (2018). Isu Laut Tiongkok Selatan: Negara-negara ASEAN Terbelah Menghadapi Tiongkok. Jurnal Global \& Strategis, 12(1), 79-100.

Darmawan, A. B. (2018). Dinamika Isu Laut Tiongkok Selatan: Analisis Sumbersumber Kebijakan Luar Negeri Tiongkok dalam Sengketa. Jurnal Ilmiah Hubungan Internasional, 14(1), 13-35.

Djalal, H. (2011). South China Sea: Contribution of $2^{\text {nd }}$ Track Diplomacy/ Workshop Process to Progressive Development of Regional Peace and Cooperation. Manila: Center for Southeast Asian Studies.

Dupuy, F. \& Dupuy, P. (2013). A Legal Analysis of China's Historic Rights Claim in the South China Sea. The American Journal of International Law, 107(1), 124141.

Economy, E. C. (2010). The Game Changer: Coping with China's Foreign Policy Revolution. Foreign Affairs, 89(6), 142-152.

Evans, T. (2003). The PRC's Relationship with the ASEAN Regional Forum: Realpolitik, Regime Theory or a Continuation of the Sinic Zone of Influence System? Modern Asian Studies, 37(3), 737-763.

Fangyin, Z. (2016). Between Assertiveness and Self-Restraint: Understanding China's South China Sea Policy. International Affairs, 92(4), 869-890.

Foot, R. (1998). China in the ASEAN Regional Forum: Organizational Process and Domestic Modes of Thought. Asian Survey, 38(5), 425-440.

Garver, J. (1992). China's Push through the South China Sea: The Interaction of Bureaucratic and National Interests. The China Quarterly, 132, 999-1028. 
Hayton, B. (2018). The Modern Creation of China's 'Historic Rights' Claim in the South China Sea. Asian Affairs, 1-13.

Hyer, E. (1995). The South China Sea Disputes: Implications of China's Earlier Territorial Settlements. Pacific Affairs, 68(1), 34-54.

International Crisis Group. (2012). Stirring up the South China Sea (I). Brussels: International Crisis Group.

Jerdén, B. (2014). The Assertive China Narrative: Why Its Wrong and How So Many Still Bought into It. The Chinese Journal of International Relations, 7(1), 47-88.

Johnston, A. I. (2013). How New and Assertive Is China's New Assertiveness? International Security, 37(4), 7-48.

Morrison, W. M. (2018). China's Economic Rise: History, Trends, Challenges, and Implications for the United States. Washington, D.C.: Congressional Research Service.

Rustandi, A. (2016). The South China Sea Dispute: Opportunities for ASEAN to enchance its policies in order to achieve resolution. Commonwealth of Australia: The Centre for Defence and Strategic Studies.

Rosati, J., Hagan, J., \& Sampson, M. (1994). Foreign Policy Restructuring: How Governments Respond to Global Change. Columbia: University of South Carolina.

Sinaga, L. (2015). China's Assertive Foreign Policy in South China Sea under Xi Jinping: Its Impact on United States and Australian Foreign Policy. Journal of ASEAN Studies, 3(2), 133-149.

Varrall, M. (2015). Chinese worldviews and China's foreign policy. Sydney: Lowy Institute.

Yi, X. (2005). Chinese Foreign Policy in Transition: Understanding China's "Peaceful Development". The Journal of East Asian Affairs, 19(1), 74-112.

Yu, P. K. (2003). The Chinese (Broken) U-shaped Line in the South China Sea: Point, Lines, and Zones. Contemporary Southeast Asia, 25(3), 405-430.

Zhao, S. (2013). Chinese Foreign Policy as a Rising Power to find its Rightful Place. Perceptions, 18(1), 101-128.

\section{Artikel Daring}

ASEAN Regional Forum. (2018). About The ASEAN Regional Forum. ASEAN Secretariat. Diakses 28 Juli 2018 pada http://aseanregionalforum.asean.org/about.html. 
BBC. (2012). Asean nations fail to reach agreement on South China Sea. Diakses 24 Agustus 2018 pada https://www.bbc.com/news/world-asia-18825148.

CIL. (2011). Document on ASEAN and South China Sea. Centre for International Law, National University of Singapore. Diakses 29 Juli 2018 pada https://cil.nus.edu.sg/wp-content/uploads/2011/06/Documents-onASEAN-and-South-China-Sea-as-of-June-2011-pdf.pdf.

Kemlu RI. (2012). ASEAN: Selayang Pandang. Kementerian Luar Negeri Republik Indonesia. $\quad$ Diakses $29 \quad$ Juli $2018 \quad$ pada https://www.kemlu.go.id/Documents/ASEAN/ASP_2012_Edisi_20.p df.

Meriam-Webster. (2018). Meaning of “assertive”. Diakses 28 Juli 2018 pada https://www.merriam-webster.com/dictionary/assertive.

MOFA of the PRC. (2015). Wang Yi on the South China Sea Issue At the ASEAN Regional Forum. Ministry of Foreign Affairs of the People's Republic of China. $\begin{array}{lllll}\text { Diakses } & 24 & \text { Agustus } & 2018 & \text { pada }\end{array}$ http://www.fmprc.gov.cn/mfa_eng/zxxx_662805/t1287277.shtml.

MOFA of the PRC. (2014). Speech by H.E. Xi Jinping President of the People's Republic of China At the Körber Foundation. Ministry of Foreign Affairs of the People's Republic of China. Diakses 28 Juli 2018 pada http://www.fmprc.gov.cn/mfa_eng/wjdt_665385/zyjh_665391/t11486 40.shtml.

Reuters. (2014). New Chinese map gives greater play to South China Sea claims. Diakses 24 Agustus 2018 pada https://www.reuters.com/article/uschina-diplomacy-map-idUSKBN0F00OI20140625.

Sinaga, L. C. (2011). Dua Dasawarsa Hubungan ASEAN-China. Pusat Penelitian Politik, LIPI. Diakses 24 Agustus $2018 \quad$ pada http://www.politik.lipi.go.id/kolom/kolom-1/politik-internasional/512dua-dasawarsa-hubungan-asean-china.

SIPRI. (2015). Recent Trends in Military Expenditure. Diakses 20 Juni 2018 dari http://www.sipri.org/research/armaments/ milex/research/armaments/milex/research/ armaments/milex/milex_database. 
South China Morning Post. (2015). China wants no talk of South China Sea at Tuesday's Asean meeting in Kuala Lumpur. Diakses 24 Agustus 2018 pada https://www.scmp.com/news/china/diplomacy-

defence/article/1846145/china-wants-no-talk-south-china-sea-tuesdaysasean.

The Guardian. (2014). Tensions rise in South China Sea as Vietnamese boats come under attack. Diakses 24 Agustus 2018 pada https://www.theguardian.com/world/2014/may/07/chinesevietnamese-vessels-clash-south-china-sea. 